\title{
Monimiaceae endémicas del Perú
}

Blanca León ${ }^{1,2}$

${ }^{1}$ Museo de Historia Natural, Av. Arenales 1256, Aptdo. 14-0434, Lima 14, Perú

2 Plant Resources Center, University of Texas at Austin, Austin TX 78712 EE.UU

blanca.leon@mail.utexas.edu

\section{Resumen}

La familia Monimiaceae es reconocida en el Perú por presentar dos géneros y casi 50 especies (Brako \& Zarucchi, 1993; Ulloa Ulloa et al., 2004; Renner \& Hausner, 2005), arbustivas y arbóreas. En este trabajo reconocemos dos especies endémicas en dos géneros, las que habitan las regiones Bosques Muy Húmedos Premontanos y Bosques Húmedos Amazónicos, entre los 140 y 1800 m de altitud. Ninguna especie endémica está representada en el Sistema Nacional de Áreas Naturales Protegidas por el Estado.

Palabras claves: Monimiaceae, Perú, endemismo, plantas endémicas.

\section{Abstract}

The Monimiaceae are represented in Peru by two genera and approximately 60 species (Brako \& Zarucchi, 1993; Ulloa Ulloa et al., 2004; Renner \& Hausner, 2005), all shrubs and trees. Here we recognize two endemic species in two genera. These endemic species of Monimiaceae are found in Very Humid Premontane Forests and Humid Lowland Amazonian Forests regions, between 140 and 1800 m elevation. No endemic Monimiaceae have been registered today within Peru's protected areas system.

Keywords: Monimiaceae, Peru, endemism, endemic plants.

\section{Mollinedia simulans J.F. Macbr.}

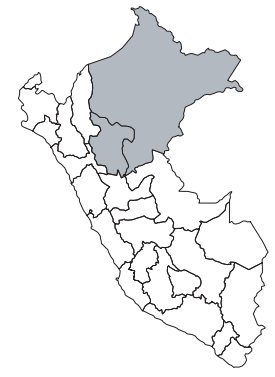

Publicación: Candollea 5: 352. 1934.

Colección tipo: L. Williams 6977

Herbarios: F, US.

Nombre común: Amoquí-ey.

Registro departamental: LO, SM.

Regiones Ecológicas: BMHP, BHA; $180-1400 \mathrm{~m}$

SINANPE: Sin registro.

Herbarios peruanos: Ninguno.

Observaciones: Arbusto conocido aparentemente de dos localidades en el nor-oriente del país. Una de las poblaciones se hallaba en la cuenca del Putumayo cerca al límite con Colombia. Este taxón fue considerado por Brako \& Zarucchi (1993) como un endemismo; sin embargo,no ha sido posible evaluarlo, ni asignarle una categoría

\section{Siparuna vasqueziana S.S. Renner \& Hausner}

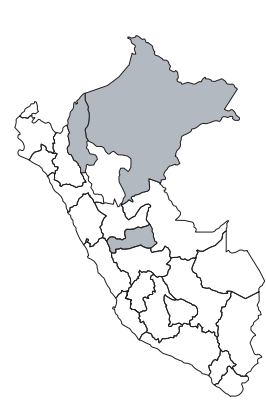

NT

Publicación: Novon 10(2): 143, f. 3, 6. 2000.

Colección tipo: R. Vásquez et al. 24278

Herbarios: F, MO, NY, W; AMAZ, HUT!, MOL, USM!

Nombre común:

Registro departamental: AM, LO, PA. Regiones Ecológicas: BMHP, BHA; $140-1200 \mathrm{~m}$.

SINANPE: ZRSC

Herbarios peruanos: AMAZ (holotipo), HUT (isotipo), USM (isotipo).

Observaciones: Árbol dioico, de hasta $5 \mathrm{~m}$ de alto conocido de poblaciones dispersas en el norte y centro del país, de las cuencas del Cenepa, Napo, Palcazú. Todas las poblaciones conocidas proceden principalmente de áreas que durante los últimos diez años han sido recién botánicamente exploradas. Poco se sabe de la estructura de la población de esta especie descrita de una planta macho. 